\section{Desenvolvimento de próstata em meninas com hiperplasia adrenal congênita: efeito dos andrógenos intraútero ou inadequado controle hormonal pós-natal?}

Larissa G. Gomes', Berenice B. Mendonça², Tânia A. S. S. Bachega ${ }^{3}$

A diferenciação da genitália externa fetal bipotencial em genitália externa masculina ou feminina dependerá da presença ou da ausência da ação androgênica, respectivamente. No homem, a testosterona secretada pelos testículos a partir da oitava semana de gestação é transformada perifericamente no andrógeno diidrotestosterona (DHT), por meio da ação da enzima $5 \alpha$-redutase 2. A DHT apresenta maior afinidade ao receptor de andrógeno do que a testosterona e age sobre a genitália externa indiferenciada, promovendo sua diferenciação em genitália externa masculina: o tubérculo genital origina a glande peniana, as pregas uretrais formam o corpo peniano, as pregas labioescrotais formam a bolsa escrotal e, a partir do seio urogenital, formam-se a uretra prostática e a próstata (1).

Logo, a próstata masculina tem a mesma origem embriológica da genitália externa e também depende da ação periférica da testosterona e principalmente da DHT. Estudos que utilizaram a metodologia de PCR em tempo real, em diferentes fases do desenvolvimento embriológico da próstata, demonstraram um pico de expressão das enzimas $5 \alpha$-redutase tipo 2 e também tipo 1 na transição do segundo para o terceiro trimestre de gestação, período que coincide com o pico de secreção da testosterona e com o aumento da velocidade de crescimento da próstata fetal (2).

Nas meninas afetadas pelas formas virilizantes da hiperplasia adrenal congênita (HAC), tais como a deficiência da 21-hidroxilase e da 11-hidroxilase, ocorre diminuição da síntese de cortisol, resultando em diminuição do feedback negativo sobre o eixo hipotálamo-hipófise-adrenal e hiperestímulo do ACTH sobre o córtex adrenal e, consequentemente, aumento da produção de andrógenos. A secreção excessiva de andrógenos a partir da sétima semana de gestação promove a virilização da genitália externa em diversos graus, podendo variar desde leve clitoromegalia até uma genitália completamente virilizada, semelhante a uma genitália masculina normal.

Apesar de a próstata ter uma origem comum à genitália externa, a detecção de próstata por ressonância magnética em meninas com HAC, até o presente estudo publicado por Paulino e cols. (3) nesta edição dos ABEM, restringiu-se a dois relatos de casos isolados $(4,5)$. As mulheres normalmente apresentam as glândulas parauretrais de Skene homólogas à próstata masculina e se localizam ao redor da uretra. As glândulas de Skene surgem ao redor da décima semana de gestação e são, assim como a próstata, formadas por tecido epitelial colunar, secretam o antígeno prostático específico (PSA), e estudos de imunoistoquímica demonstraram a presença de receptor androgênico (6). Logo, pode-se inferir que a exposição pré-natal precoce aos andrógenos poderia levar ao desenvolvimento das glândulas de Skene em tecido prostático nas meninas com
Doutora em Endocrinologia pela Faculdade de Medicina da Universidade de São Paulo (FMUSP)

2 Professora titular da Disciplina de Endocrinologia da FMUSP

${ }^{3}$ Professora livre-docente em Endocrinologia pela FMUSP, médica-assistente da Disciplina de Endocrinologia do Hospital das Clínicas da FMUSP, São Paulo, SP, Brasil

Correspondência para: Tânia A. S. S. Bachega Laboratório de Hormônios e Genética Molecular LIM 42 Hospital das Clínicas Av. Dr. Enéas de Carvalho Aguiar, 155, $2^{\circ}$ andar, bloco 6 05403-900 - São Paulo, SP, Brasil tbachega@usp.br 
HAC. No entanto, restam algumas perguntas: qual seria o período de exposição androgênica, pré-natal ou pós-natal, determinante para o desenvolvimento do tecido prostático? Por que o tecido prostático não é identificado em todas as pacientes com a forma clássica da HAC? Poderiam estar envolvidos fatores genéticos nesta manifestação fenotípica variável?

Estudo em modelo animal com ratas expostas no período intraútero a diferentes doses de propionato de testosterona demonstrou o desenvolvimento de tecido prostático-símile, sendo esse efeito dose-dependente (7).

As duas pacientes com HAC descritas inicialmente na literatura $(4,5)$, nas quais foi observada a presença de tecido prostático por ressonância magnética, apresentaram grau de virilização da genitália externa Prader III-IV, o que sugere intensa exposição androgênica no período pré-natal. É sabido que outros fatores, além das concentrações de testosterona, podem influenciar o grau de virilização da genitália externa em mulheres com HAC. Demonstrou-se previamente que o trato polimórfico de repetições CAG no gene de receptor de andrógenos, o qual altera sua atividade de transativação, influencia o grau de virilização da genitália externa nas pacientes com HAC (8). Uma vez que os diferentes tecidos apresentam sensibilidade variável à ação dos andrógenos, supõe-se que polimorfismos em genes relacionados à ação dos andrógenos e/ou seu metabolismo poderiam estar relacionados ao achado radiológico da evidência de tecido prostático em mulheres com HAC. Essa hipótese já foi demonstrada em ratas apresentando expressão alterada da enzima 17ßHSD tipo 1, homóloga a de humanos, que converte androstenediona em testosterona, uma vez que essas ratas apresentaram o desenvolvimento de próstata além de virilização da genitália externa $(9)$.

Nesta edição dos ABEM, Paulino e cols. (3) demonstraram a presença de próstata em 15,6\% das meninas portadoras da forma clássica de HAC, por meio da utilização da ressonância magnética como padrão-ouro. A presença de tecido prostático em $5 / 32$ das meninas com HAC mostrou-se elevada e, provavelmente, decorreu de uma investigação sistemática por intermédio de método radiológico sensível. A análise da correlação da presença de próstata com o grau de virilização da genitália externa pelo Prader, em estudo futuro, poderá reforçar o papel da ação androgênica intraútero no desenvolvimento da próstata no sexo feminino.

Adicionalmente, não se pode afastar a hipótese de que o crescimento da próstata poderia ser corroborado pela exposição a elevadas concentrações de andrógenos no período pós-natal, quer por diagnóstico tardio nas pacientes portadoras da forma virilizantes simples, quer por falta de aderência ao tratamento, resultando em inadequada supressão androgênica.

A importância do hiperandrogenismo pós-natal no desenvolvimento e/ou no crescimento prostático foi demonstrada em estudo que administrou testosterona para ratas adultas, em doses que simulavam estado hiperandrogênico. Foi observado aumento da proliferação, diferenciação e atividade secretória do tecido prostático feminino, valendo notar que o processo de proliferação do tecido prostático nessas roedoras foi semelhante ao encontrado no desenvolvimento fetal da próstata masculina em camundongos (10). Portanto, esses dados sugerem que o hiperandrogenismo pós-natal também poderia ter influência no desenvolvimento da próstata nas pacientes com HAC. A paciente com evidência de tecido prostático descrita por Subramanian e cols. (5) teve seu diagnóstico de forma virilizante da deficiência da 21-hidroxilase realizado somente aos 14 anos de idade. Embora um dos principais objetivos do trabalho de Paulino e cols. (3) fosse a avaliação da dosagem de PSA na detecção da presença de tecido prostático, torna-se de grande relevância o conhecimento da idade ao diagnóstico assim como o grau de controle hormonal das cinco pacientes com próstata.

Como a ressonância magnética apresenta alto custo e não deve ser feita de forma sistemática, Paulino e cols. (3) demonstraram que o PSA pode ser um bom preditor da presença de tecido prostático em pacientes do sexo feminino com HAC; porém, vale reforçar a falta de especificidade do método. Como já pontuado no artigo original, o PSA pode ser detectável em até $10 \%$ das mulheres normais por ser expresso também em outros tecidos. Logo, o uso da dosagem do PSA como ferramenta de rastreamento na detecção de tecido prostático deve ainda ficar restrito a centros de investigação, visto que o achado de PSA detectável em meninas pode ser um resultado falso-positivo e pelo fato de que a presença de tecido prostático pode gerar grande ansiedade para a família.

$\mathrm{O}$ alerta fundamental sobre o frequente achado de próstata neste interessante trabalho de Paulino e cols. (3) reforça a importância do adequado controle hormonal no tratamento da HAC, visando à normalização das concentrações de testosterona e androstenediona, ajustados para idade e sexo, a fim de se evitar também o estímulo à proliferação desse tecido, aumentando a 
probabilidade do desenvolvimento de hiperplasia, displasia e até mesmo de neoplasia prostática, riscos que nas mulheres afetadas por HAC ainda precisam ser determinados.

\section{REFERÊNCIAS}

1. Jost A. A new look at the mechanisms controlling sex differentiation in mammals. Johns Hopkins Med J. 1972;130(1):38-53.

2. Radmayr C, Lunacek A, Schwentner C, Oswald J, Klocker H, Bartsch G. 5-alpha-reductase and the development of the human prostate. Indian J Urol. 2008;24(3):309-12.

3. Paulino MCR, Steinmetz L, Menezes Filho HC, Kuperman H, Della MannaT, Vieira JGH, et al. Pesquisa de tecido prostático em pacientes $46, X X$ portadoras da forma clássica de hiperplasia congênita das supra-renais. Arq Bras Endocrinol Metab. 2009;53(6):717-21.

4. Klessen C, Asbach P, Hein PA, et al. Complex genital malformation in a female with congenital adrenal hyperplasia: evaluation with magnetic resonance imaging. Acta Radiol. 2005;46:891-4.
5. Subramanian S, Gamanagatti S, Sharma R. MR demonstration of a prostate gland in a female pseudohermaphrodite. Pediatr Radiol. 2006;36:1194-6.

6. Zaviacic M, Ablin RJ. The female prostate and prostate-specific antigen. Immunohistochemical localization, implications of this prostate marker in women and reasons for using the term "prostate" in the human female. Histol Histopathol. 2000;15(1):131-42.

7. Hotchkiss AK, Furr J, Makynen EA, Ankley GT, Gray Jr LE. In utero exposure to the environmental androgen trenbolone masculinizes female Sprague-Dawley rats. Toxicol Lett. 2007;174(1-3):31-41.

8. Rocha RO, Billerbeck AE, Pinto EM, Melo KF, Lin CJ, Longui CA, et al. The degree of external genitalia virilization in girls with 21-hydroxylase deficiency appears to be influenced by the CAG repeats in the androgen receptor gene. Clin Endocrinol (Oxf). 2008;68(2):226-32.

9. Saloniemi T, Welsh M, Lamminen T, Saunders P, Mäkelä S, Streng T, et al. Human HSD17B1 expression masculinizes transgenic female mice. Mol Cell Endocrinol. 2009;301:163-8.

10. Santos FC, Leite RP, Custodio AM, Carvalho KP, Monteiro-Leal LH, Santos $A B$, et al. Testosterone stimulates growth and secretory activity of the female prostate in the adult gerbil (Meriones unguiculatus). Biol Reprod. 2006;75(3):370-9. 